\title{
Quantitative Research on Value Added of Production Process Based on Value Chain \\ Xiaobing Pei ${ }^{a}$, Fangjian Shang ${ }^{\text {b }}$
}

Tianjin University of Technology, Tianjin 300384, China.

a yingguangjian@126.com, b517251674@qq.com

Keywords: Value Added; Core Competence; Principal Component Analysis.

\begin{abstract}
As the market competition becomes fiercer and fiercer, the requirements for the production department are also getting higher and higher. How to identify the value added in the production process and determine the most competitive link in the production process has become one of the most important issues. By summarizing the factors that affect the excess profits, the principal component analysis method is used to allocate the excess profits to each the production processes so as to identify the value added of each production process. Recognition of value added and determination of core competence links have some practical significance for maintaining core competitiveness, maintaining the competitive advantage of enterprises and realizing long-term and steady development of the enterprises.
\end{abstract}

\section{Introduction}

Faced with drastic changes in the world market and competition intensified, the requirements for the production sector is also getting higher and higher, only lower prices for customers and create greater value, to gain a competitive advantage, from today's harsh competitive environment come to the fore and achieve enduring development. The various activities of an enterprise can be expressed through the value chain, which can clearly show how customer perceived value is generated through a series of activities. The emergence of the value chain plays an important role in guiding the practice of enterprise management. Through coordination and integration of various value activities, enterprises can be helped to maximize their value creation. This paper attempts to identify the value added in the production process from a quantitative point of view, so as to determine the most competitive part in the production process of an enterprise, which plays a significant role in reducing production costs, improving product profits and maintaining a sound development of the enterprise.

\section{Production Process in All Aspects of Value Added Value of Quantification}

\subsection{The Composition of Profit}

The profit composition of an enterprise can be divided into two parts: average profit in the industry and enterprise excess profit. The average industry profit is the revenue an enterprise may spend on projects with the same risk, which is also called the opportunity cost of the enterprise. Homogeneous products in a perfectly competitive market, companies can only get the average profit of the industry but cannot get the excess profits. An enterprise may be outperforming its industry because of leadingedge new technologies, greater bargaining power or for other reasons that make it more expensive than other businesses or less expensive than others the average level of profit, that is excess profits of the enterprise.

Value Stream Diagram is a tool that helps explain the value-added situation. People adopt the way of value flow chart, according to the order from the customer to the supplier, according to the production process of the product, chart the material flow and the information flow in each step, the image describes the material flow and the information flow. Through drawing up the current value flow chart of the enterprise, it helps enterprises to analyze value-added and non-value-added activities in the production process, find out where wasted, identify areas for improvement, and continue to take certain measures to improve, reduce and even eliminate non-value-added activities. Value Streaming helps businesses reduce waste, shorten the production cycle, thereby increasing the value 
of the enterprise. The value flow diagram defines the value-added measures expressed in time for each process. Although the value appreciation is explained to a certain extent, it cannot be measured in terms of value.

In order to quantitatively analyze the value-added process, this paper finds out the factors that affect the profit composition by summarizing the reasons for the formation of profits and uses the principal component analysis method to quantitatively allocate the excess profits of the products to all the production processes.

\subsection{Selection of Indicators}

In the production process, the process of making the average profit of the enterprise in the industry is the average technical level in the industry, which exceeds the average technical level of the industry and constitutes the excess profit of the enterprise. Comparing the technical level of an enterprise with the average technical level of an industry, the factors that affect the technical level constitute an indicator of profit distribution. In selecting indicators, this article follows the following principles:

(1) Importance: The index selected should contain important items that reflect the core competitiveness. If the omission or error of the index will affect the judgment of the core competitiveness of the enterprise, the index is of importance;

(2) quantifiable: quantification of value-added requirements Selected indicators must be measurable for analysis;

(3) Comparability: In order to observe the changes in the core competitiveness of enterprises, the indicators chosen should be comparable at different times.

(4) Controllability: Enterprises should select the indicators that have the ability to control, and in some cases, they are incapable of making any changes, then they should temporarily abandon the selection of indicators in this respect.

According to the above principle of selection of indicators, combined with the relevant literature, this paper selects the following indicators as the basis for the distribution of excess profits:

(1) the number of patents: The number of patents that can be used in the production of a patent is higher than the average level in the industry. The greater the value-added value, the more profits should be allocated to the link.

(2) Proficiency of workers: When a worker's proficiency in a certain process is higher than the average level of the industry, the time spent in the industry will be shorter than the average time in the industry. Because of the time value of funds, the less time it takes, the more occupied value low. When the final value is constant, the lower the cost of consumption, the greater the value added will be. In this paper, we choose the number of processing unit time as an indicator of worker proficiency.

(3) advanced technology: advanced technology or can make the product have higher quality and higher value; or can increase productivity and reduce resource consumption. When a link has a higher than the industry average process level, the value of the link the greater the value. This article selects the product qualification rate as an indicator of advanced technology.

(4) Inventory: the more inventory a certain production process takes, the more non-value-added time will be in this link. As the capital has the time value, the higher the capital cost will be, and accordingly, the added value of this link the smaller.

(5) Training time: Employee training can improve the overall quality of employees in the enterprise, improve the production efficiency in the production process, and ensure the production quality of the products. The longer the training time for skilled workers on a production link, the greater the added value of the link will be.

(6) equipment failure rate: the probability of failure in a certain period of time. The lower the failure rate of a production link in the production process, the more valuable time it will add to the value chain.

In summary, this article selected the number of patents, the number of processing units within a time, product qualification rate, inventory, staff training time, equipment failure rate, these six items as an indicator of excess profits. 


\subsection{The Method of Distribution of Excess Profits}

In this paper use principal component analysis of profit distribution to production chain. The principal component analysis can avoid a large number of information overlap, pay attention to the main contradictions and find out the rules existing between the variables with the loss of a small amount of information, and simplify the problems and enhance the efficiency. Moreover, the data used by principal component analysis are objective data, avoiding the influence of subjective factors, making the distribution of excess profits more accurate.

Six factors that affect the added value of the production process are involved, which are denoted by $\mathrm{X}_{1}, \mathrm{X}_{2}, \ldots \ldots, \mathrm{X}_{6}$, respectively. These six indexes constitute a 6 -dimensional random vector $\mathbf{X}=$ $\left(\mathrm{X}_{1}, \mathrm{X}_{2}, \ldots \ldots, \mathrm{X}_{6}\right)^{\prime}$. Let the mean of the random vector $\mathrm{X}$ be $\mu$, linearly transform $\mathrm{X}$ to form a new synthetic variable, denoted by $\ddot{y}$ then the new synthetic variable can be linearly represented by the original variable and satisfy the following equation:

$$
\left\{\begin{array}{c}
Y_{1}=\mu_{11} X_{1}+\mu_{21} X_{2}+\ldots+\mu_{61} X_{6} \\
Y_{2}=\mu_{12} X_{1}+\mu_{22} X_{2}+\ldots+\mu_{62} X_{6} \\
\cdots \ldots . \\
Y_{n}=\mu_{1 n} X_{1}+\mu_{2 n} X_{2}+\ldots+\mu_{6 n} X_{6}
\end{array}\right.
$$

Find the new integrated variables $Y_{1}, Y_{2}, \ldots \ldots, Y_{n}$ which are independent of each other, as the first, the second ... the nth principal component of the original variable. Among them, the proportion of each comprehensive variable in total variance decreases in sequence. Take the first s principal components whose cumulative contribution rate is greater than $85 \%$, multiply the corresponding coefficient of each of the first $\mathrm{s}$ principal components $\mathrm{Y}_{1}, \mathrm{Y}_{2}, \ldots \ldots, \mathrm{Y}_{\mathrm{s}}$ by the contribution ratio of the principal component, and then sum, and then Divided by the sum of the contribution rates of the first s principal components extracted, an integrated weight model is obtained:

$$
\begin{gathered}
\mathrm{Y}_{z}=\mu_{1} \mathrm{X}_{1}+\mu_{2} \mathrm{X}_{2}+\ldots+\mu_{6} \mathrm{X}_{6} \\
\mathrm{~V}_{\mathrm{zi}}=\sum_{\mathrm{j}=1}^{6} \mu_{1} * \mu_{\mathrm{ij}} \\
\omega_{i}=\mathrm{V}_{\mathrm{zi}} / \sum_{\mathrm{j}=1}^{6} \mathrm{~V}_{\mathrm{zi}}
\end{gathered}
$$

The coefficient of each indicator in the integrated weight model is the weight on which the excess profit is distributed.

Through principal component analysis to determine the weight of all aspects of the production process, the excess profits allocated to all production processes in accordance with the weight of the link in the industry average profit plus the distribution of excess profits, constitutes the value of the link.

\section{Summary}

This article summarizes the factors that affect the value added in the production process and uses the principal component analysis to divide the excess profit according to six indicators. The selected index is the universal indicator. When the enterprise allocates, it also needs to consider the characteristics of the industry and select the most suitable indicators of the industry, in order to more accurately allocate excess profits. Identify the value of the largest part of the added value is the most competitive part of the way through the identification of the core competitiveness of enterprises from the overall level of specific to the production level. Only by maintaining the core competitiveness of enterprises in the part of the advantages, in order to ensure the sustainability of profits, so as to achieve long-term business health and development. 


\section{References}

[1]. Barney J B. Firm Resource and Sustained Competitive Advantage[J]. Journal of Management, 1991, 17(1):99-120.

[2]. Nobre F S. Core competencies of the new industrial organization[J]. Journal of Manufacturing Technology Management, 2011, 22(4):422-443.

[3]. Barenji R V, Hashemipour M, Guerra-Zubiaga D A. A framework for modelling enterprise competencies: from theory to practice in enterprise architecture[J]. International Journal of Computer Integrated Manufacturing, 2015, 28(8):791-810. 